\title{
AOR
}

Selected Papers of \#AolR2019:

The $20^{\text {th }}$ Annual Conference of the Association of Internet Researchers Brisbane, Australia / 2-5 October 2019

\section{FROM CHASTITY BELTS TO SMART FROCKS: THE PROMISE OF RAPE DETERRENT TECHNOLOGY}

\author{
Dr Alex Bevan \\ University of Queensland \\ Dr Caroline Wilson-Barnao \\ University of Queensland \\ Assistant Professor Robyn Lincoln \\ Bond University
}

\begin{abstract}
In 2018, Schweppes partnered with Ogilvy Brazil to design a smart dress that used touch-sensors to illustrate how women are groped in nightclubs (Dickson 2018). The dress exemplifies an array of intimate digital devices that mobilize smart technology aimed at preventing sexual assault in public space. It represents a growing category of corporeal technologies ostensibly designed to protect and potentially capture probative evidence for previously silenced publics. Other categories include smart phone apps or wearable jewellery that send alerts or alarms to smart bracelets that monitor alcohol consumption in order to provide more authentic indicators of sexual consent (Bivens and Hasinoff 2018, White and McMillan 2019). Devices like the Ogilvy dress and the quantification they render, subject women to greater levels of surveillance, responsibilize them for personal safety, and reinscribe a silencing dynamic by positioning the technology as more reliable evidence of women's experience than their verbal statements. These devices are undertheorized as potential erosions of the legitimacy of individual testimony and experience that are part of digital culture more broadly speaking (Couldry 2010). The devices are problematically framed with technological solutionism to what are complex and contextually-sensitive social issues, and their promise undermines trust in the digital and online to prevent sexual harassment and assault victimization.
\end{abstract}

Suggested Citation (APA): Bevan, A., Wilson-Barnao, C., \& Lincoln, R. (2019, October 2-5). From chastity belts to smart frocks: The promise of rape deterrent technology. Paper presented at AoIR 2019: The $20^{\text {th }}$ Annual Conference of the Association of Internet Researchers. Brisbane, Australia: AolR. Retrieved from http://spir.aoir.org. 


\section{Summary}

Schweppes partnered with Ogilvy Brazil in designing a smart dress that used touchsensors to track how three women were physically harassed in a nightclub. As the women moved through the venue, data from the sensory dress were sent to a control centre, which lit up a total of 157 times in four hours demonstrating the extent to which they received unwanted attention (Dickson 2018). The experiment concurs with interview research revealing that more than half of young adult women in licensed premises in entertainment precincts had endured unwanted sexual attention including touching in the past three months (Miller et al., 2019). The smart dress however is emblematic of the growth of a category of new devices marketed to women and girls and designed to make them feel safer in public space. For example, the Stiletto is a wearable technology disguised as a piece of jewellery that is also able to place emergency calls on the user's behalf. A fundamental claim of such rape deterrent devices is the assurance of enhanced safety, agency, and the ability to legitimize claims of sexual assault.

In this paper we situate the discussion of rape deterrent technologies among current discourses on the monitoring and datafication of the body (Andrejevic 2002, Smith 2016, Lyon 2014). We study a range of smart devices and their promises in order to set up an analytical comparison. We examine the extent to which these devices provide solutions and explore their claims to provide protection while commodifying forms of bodily surveillance. Acknowledging that devices of this nature are not new, we consider the longer trajectory of how wearables such as chastity belts have been used to address social problems.

Over time, the role of these devices has transformed from their use to signify the modesty of the wearer to an apparatus that is promoted as giving women back control over their own bodies. By turning to examine contemporary devices, we highlight the ideologies and technological solutionism that accompany the current tranche of rape deterrent wear. Our aim is to scrutinize the promises offered that emphasize empowerment and safety and yet denote misplaced trust in the digital and online spheres. Such notions of safety rely on the active participation of users who make their bodies available to devices that enact various forms of digital surveillance. While acknowledging potential benefits of these inventions, we question their role in outsourcing the work of addressing broader social concerns and responsibilization of the wearer.

The utopic discourse on the democratizing potentials of new technologies coexists with the history of how these same technologies can also disenfranchise vulnerable publics according to race, gender, class, and geographic location. This phenomenon is wellcovered by the academic literature on the digital divide (Warschauer 2003, Van Dijk 2005, Ragnedda 2018, Caprio, 2018). Indeed, the history of disruptive technologies demonstrates how they often initially reinscribe the marginalization of precisely the publics most in need of access to the public sphere (Marneffe 1991). The histories of gender-based marginalization and technological innovation as a popular discourse are deeply entangled. The process of technological disruption is always bound up with the silencing and elision of vulnerable populations. This is because institutions of power 
shape technological "progress" and the ways inventions are ultimately disseminated and narrativized (Marvin, 1988). It would seem that the affordances of anti-rape smart devices invite trust that the digital and online will offer protection and that eventually crowdfunded products will address the wider issues of sexual violence. There is promise that smart frocks and jewellery may permit data gathering and thereby enhance knowledge about the prevalence and incidence of unwanted touching, whether in nightclubs in metro districts or on public transport in poorer locations. Concomitantly, there appears a patent false promise that these apps and wearables sending alerts and alarms are likely to prevent sexual assaults and inevitably erode trust in connected solutions.

\section{References}

Andrejevic, M. (2002). The work of being watched: Interactive media and the exploitation of self-disclosure. Critical Studies in Media Communication, 19(2): 230-248.

Bivens, R. \& Hasinoff, A.A. (2018). Rape: Is there an app for that? An empirical analysis of the features of anti-rape apps. Information, Communication \& Society, 21(8): 10501067.

Carpio, G.G. (2018). Racial projections: Cyberspace, public space, and the digital divide. Information, Communication and Society, 21(2): 174-190.

Couldry, N. (2010). Why Voice Matters: Culture and Politics After Neoliberalism. Thousand Oaks, CA: Sage Publications.

Day, A. \& Fernandez, E., (eds), (2015). Preventing Violence in Australia. Sydney: Federation Press.

De Marneffe, D. (1991). Looking and listening: The construction of clinical knowledge in Charcot and Freud. Signs: Journal of WOmen in Culture and Society, 17(1): 71-111.

Dickson, E.K. (November 29, 2018). An ad agency created a smart dress to prove women get groped at clubs. Vox. Accessed at: https://www.vox.com/thegoods/2018/11/29/18118402/ogilvy-schweppes-smart-dress-harassment

Lyon, D. (2014). Surveillance, Snowden, and big data: Capacities, consequences, critique. Big Data \& Society, 1(2): 1-13.

Marvin, C. (1988). When Old Technologies Were New: Thinking About Electric Communication in the Late Nineteenth Century. New York: Oxford University Press.

Miller, P., et al., (2019). Queensland Alcohol-Related Violence and Night Time Economy Monitoring (QUANTEM), Final Report (April). Deakin University, Geelong Australia. Prepared for the Queensland Government Department of Premier and Cabinet.

Ragnedda, M. (2018). Conceptualizing digital capital. Telematics and Informatics, 35(8): 2366-2366. 
Smith, G. (2016). Surveillance, data, and embodiment: On the work of being watched. Body and Society, 22(2): 108-139.

Van Dijk, J. (2005). The Deepening Divide. Thousand Oaks, CA: Sage Publications.

Warschauer, M. (2003). Technology and Social Inclusion: Remaking the Digital Divide. Cambridge, MA: MIT Press.

White, D. \& McMillan, L. (2019). Innnovating the problem away? A critical study of antirape technologies. Violence Against Women, online: 1-21. DOI: 10.1177/1077801219856115. 